develop. Treatment of susceptible organisms early in the disease with a combination of intravitreal amphotericin and oral imidazoles, such as fluconazole or ketoconazole, may, however, be curative and reduce or prevent the need for surgical intervention.?

Even in those eyes with a vigorous vitritis or anterior uveitis, the number of organisms is low $^{12}$ and microbiological confirmation of infection by needle biopsy of the vitreous has a low success rate, ${ }^{8}$ in contrast with that in bacterial endophthalmitis. Thus, there is a tendency to treat these eyes empirically avoiding vitrectomy, often to good effect, but the patient described above illustrates the value of isolating the infecting organism and determining its drug sensitivity. Because of his dependency on intravenous feeding, oral imidazoles could not be given, and of the available intravenous preparations, the organism was sensitive only to miconazole.

Although intravenous miconazole can penetrate the eye and achieve adequate therapeutic levels, this was not effective in this patient as demonstrated by the clinical appearance of progression of the lesion in the right eye. In eyes that are not very inflamed, the blood-retinal barrier may remain intact and systemic drug penetration of the eye may not be adequate. Intravenous amphotericin $B$ has poor ocular penetration even in inflamed eye but may be effective if used in sufficiently high dosage, ${ }^{9}$ or after vitrectomy when the bloodretinal barrier has been compromised. 10 The overall effect of vitrectomy on the therapeutic efficacy of intracameral amphotericin B is difficult to gauge since ocular clearance of the drug is also enhanced. ${ }^{10}$

Alternative choices of therapy for this patient included repeated intravitreal injections of amphotericin B at weekly intervals or intravitreal injection of miconazole; in view of the limited therapeutic options, progressive retinal changes, and good outcome following surgery in the left eye, right pars plana vitrectomy and repeat intravitreal injection of amphotericin B were undertaken. This allowed debridement of the lesion and resulted in an excellent clinical outcome. In Candida endophthalmitis, progression of lesions in spite of medical treatment is an indication for vitrectomy to ensure that appropriate drug therapy is given and to reduce the risk of sight threatening complications.

The authors would like to thank Mr R J Cooling consultant vitreoretinal surgeon, for his valuable advice on the clinical management of this patien

HMA TOWLER $S$ LIGHTMAN

Department of Clinical Ophthalmology

M MATHESON

Department of Pathology Moorfields Eye Hospital, London

Correspondence to: Mr Hamish MA Towler,
Whipps Cross Hospital, Whipps Cross Road, Whipps Cross Hospital, Whipps
Leytonstone, London E11 INR.

Accepted for publication 14 August 1995

1 Edwards JE Jr, Foos RY, Montgomerie JZ Guze LB. Ocular manifestations of Candida septicemia: review of seventy-six cases of hepticemia: review of seventy-six cases of hematogenous Candida

2 Griffin JR, Pettit TH, Fishman LS, Foos RY Blood-borne Candida endophthalmitis: clinical and pathologic study of 21 cases. Arch Ophthalmol 1973; 89: 450-6.

3 Montgomerie JZ, Edwards JE Jr. Association of infection due to Candida albicans with intravenous hyperalimentation. F Infect Dis 1978; 137: $197-20$

4 Aguilar GL, Blumenkrantz MS, Egbert PR McCulley JP. Candida endophthalmitis afte intravenous drug abuse. Arch Ophthalmol 1979; 97: 96-100.

5 Servant JB, Dutton GN, Ong-Tone L, Barrie T Davey C. Candidal endophthalmitis in Glaswegian heroin addicts: report of an epidemic. Trans Ophthalmol Soc UK 1985; 104 297-308.

6 Stern GA, Fetkenhour CL, O'Grady RB. Intravitreal amphotericin B treatment of Candida endophthalmitis. Arch Ophthalmol 1977; 95: 89-93.

7 Gallo J, Playfair J, Gregory-Roberts J, Grunstein $H$, Clifton-Bligh $P$, Billson $F$. Fungal endophthalmitis in narcotic abusers: medical and surgical therapy in 10 patients. Med $\mathcal{F}$ Aust 1985 142: $386-8$

8 Snip RC, Michels RG. Pars plana vitrectomy in the management of endogenous Candid endophthalmitis. Am $f$ Ophthalmol 1976; 82: 699-704

9 Green WR, Bennett JE, Goos RD. Ocular penetration of amphotericin B: a report of laboratory studies and a case report of postsurgical tory studies and a case report of postsurgical Ophthalmol 1965; 73: 769-75.

10 Doft BH, Weiskopf J, Nilsson-Ehle I, Wingard LB Jr. Amphotericin clearance in vitrectomized versus nonvitrectomized eyes. Ophthalmology 1985; 92: 1601-5.

\section{Congenital stationary nightblindness in a patient with osteopetrosis}

EDITOR,-Osteopetrosis, which is characterised by increased skeletal mass due to failure of bone absorption by osteoclasts, is classified into two categories. The juvenile onset type is an autosomal recessive disorder, marked by frequent fractures, anaemia, blindness, low resistance to infection, and early death. ${ }^{1}$ Adult onset type, inherited as an autosomal dominant trait, takes a more benign course; frequently asymptomatic and found radiologically. ${ }^{2}$

Ocular anomalies associated with osteopetrosis are optic atrophy, papilloedema, nystagmus, strabismus, impairment of extraocular motility, ptosis, and exophthalmos. ${ }^{3}$ However, there has been no report of association between congenital stationary nightblindness (CSNB) and osteopetrosis. We examined electrophysiologically a patien with adult onset osteopetrosis who complained of nightblindness.

\section{CASE REPORT}

The patient was a 36-year-old woman whose parents were first cousins. She and two of her three siblings had had nightblindness and high myopia since childhood, although we had no chance to examine her siblings. A chest $x$ ray showed increased bone density and diffusely sclerotic bone structures. Computed tomography scan showed diffuse thickening and increased density of the skull bones (Fig 1). Narrowing of the optic canals was not observed radiologically. She was diagnosed as having adult onset osteopetrosis.

Her visual acuity was $20 / 25$ with a correction of $-8.0 \mathrm{D}$ in both eyes. No abnormality was observed in eye movement or in the pupils. Funduscopically, myopic changes were observed. The margins of the optic discs were clear and the colour was good, although the discs were tilted (Fig 2). The dark adaptation curve showed absent rod-dark adaptation. The light peak/dark trough ratios on electro-oculogram were $2 \cdot 2$.

The electroretinogram (ERG) was recorded using contact lens electrodes (Kyoto-Contact-Lens, AE, Kyoto, Japan) as active electrodes. The light source was a stroboscopic light (Nihon-Kohden, SLS3100, Tokyo). After 30 minutes of dark adaptation,
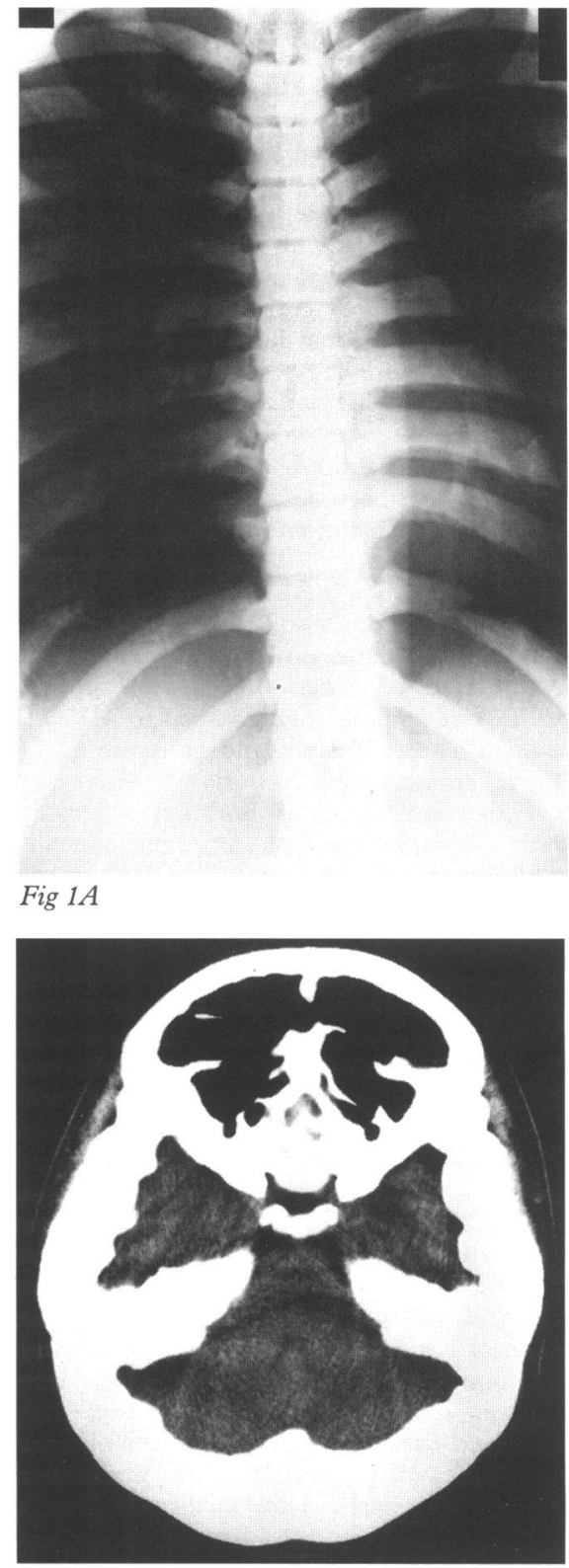

Fig $1 B$

Figure 1 (A) Chest $\mathrm{x}$ ray showed increased bone density and diffusely sclerotic bone structures indicative of osteopetrosis.

(B) Computed tomographic scan of the head showed diffuse thickening and increased density of the skull bones.

scotopic b-wave, photopic flickering, and a single white flash responses were recorded with a blue dim light, $30 \mathrm{~Hz}$ flickering light, and a white flash light of $40 \mathrm{~J}$, respectively. Single flash ERGs showed negative-type ERG. Scotopic ERGs were extinguished (Fig 2C).

\section{COMMENT}

CSNB has been classified into CSNB with abnormal fundi (Oguchi's disease and fundus albipunctatus) and CSNB with normal fundi. ${ }^{4}$ In CSNB with normal fundi, the fundus appearance is essentially normal, although some patients show changes associated with high myopia ${ }^{5}$ or optic disc changes (tilted, pale, or dysplastic) ${ }^{6}$ CSNB with normal fundi, which is inherited as an autosomal recessive, autosomal dominant, or $\mathrm{X}$ linked recessive trait, is classified into two types. Type I shows a markedly reduced ERG. Type II shows a negative type ERG; a normal a-wave with a markedly reduced or 


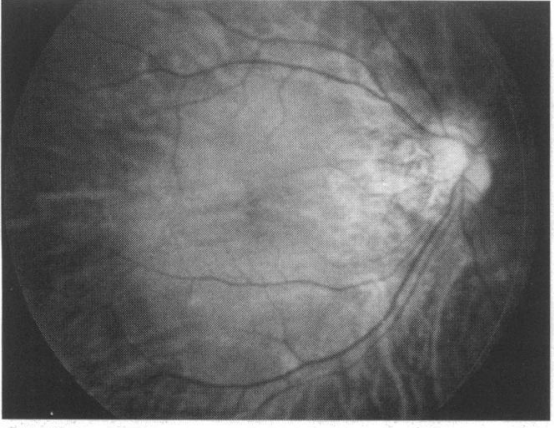

Fig $2 A$

Patient

$30 \mathrm{~Hz}$ Flicker

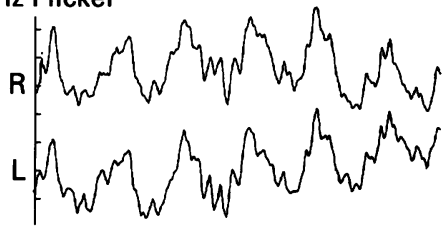

$5 \mu \mathrm{V}$

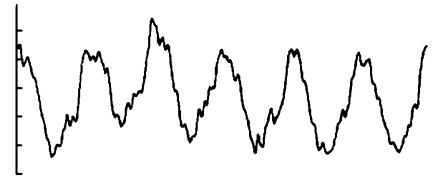

$15 \mu \mathrm{V}$

Scotopic

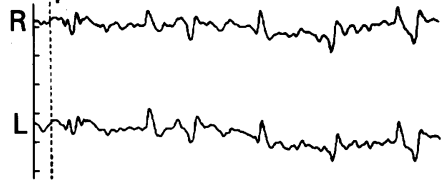

Bright white flash

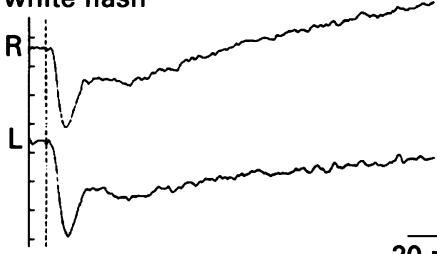

$20 \mathrm{~ms}$

Fig $2 C$

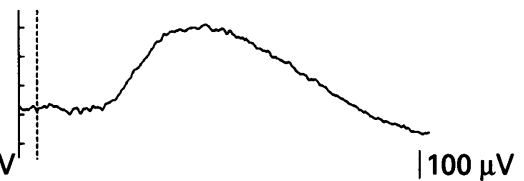

Figure 2 Fundus appearance $((A)$ right eye, $(B)$ left eye). Myopic changes were observed. Optic discs were tilted; however, the colour of the disc was good. (C) Electroretinogram (ERG). Single white flash ERG showed a negative-type ERG (that is, a normal a-wave with a markedly reduced $b$-wave). The oscillatory potentials were absent. Scotopic ERG were extinguished in both eyes. Photopic flicker responses were only slightly reduced compared with those of a normal subject.

absent b-wave. ${ }^{4}$ Type II CSNB is further divided into complete and incomplete types. ${ }^{5}$ Complete type CSNB shows refractive error ranging from moderate to high myopia and corrected visual acuity ranging from $20 / 200$ to 20/25. Dark adaptation shows absent rod-dark adaptation. On single flash ERG, oscillatory potentials are absent. The scotopic ERG is extinguished whereas the photopic flicker responses are normal or subnormal. Accordingly, this patient was diagnosed as complete type CSNB.

Patients having osteopetrosis with visual disturbance caused by compression of the optic canal have been recommended for optic nerve decompression. ${ }^{7}$ However, primary retinal degeneration has been reported as a cause of visual disturbance: three cases of reduced or extinguished ERGs, ${ }^{8}$ two cases of macular degenerátion, ${ }^{9}$ and a case of marked atrophy of the rod and cone layer with degenerative outer nuclear layer. ${ }^{10}$ In our case, CSNB was suggested to be the cause of visual dysfunction. Electrophysiological examination is important in detecting retinal dysfunction in patients with osteopetrosis.

YOSHIE MATSUI SATOSHI OKINAM SHINII OONO Department of Ophthalmology, Saga Medical School, fapan MAKOTO MATSUI Saga Medical School, fapan
Correspondence to: Yoshie Matsui, MD, Department of Ophthalmology, Saga Medical School, Nabeshima, Saga 849, Japan.

Accepted for publication 9 August 1995

1 Enell H, Pehrson M. Studies on osteopetrosis. 1. Clinical report of three cases with genetic considerations. Acta Pediatr 1958; 47: 279-87.

2 Johnston CC, Lavy N, Lord T, Vellios F, Merritt AD, Deiss WP. Osteopetrosis. A clinical, genetic, metabolic, and morphologic study of the dominant inherited, benign form. Medicine the dominant inhe

3 Klintworth GK. The neurologic manifestations of osteopetrosis (Albers-Schönberg's disease). Neurology 1963; 13: 512-9.

4 Carr RE. Congenital stationary night blindness. In: Heckenlively JR, Arden GB, eds. Principles and practice of clinical electrophysiology of vision. St Louis: Mosby Year Book, 1991; 96: 713-20.

5 Miyake Y. Incomplete-type congenital stationary night blindness. In: Heckenlively JR, Arden $\mathrm{GB}$, eds. Principles and practice of clinical electrophysiology of vision. St Louis: Mosby Year physiology of vision. St

6 Heckenlively JR, Martin DA, Rosenbaum AL Loss of electroretinographic oscillatory potentials, optic atrophy, and dysplasia in congenita stationary night blindness. Am $\mathcal{f}$ Ophthalmol 1983; 96: 526-34.

7 Haines SJ, Erickson DL, Wirtschafter JD. Optic nerve decompression for osteopetrosis in early childhood. Neurosurgery 1988; 23: 470-5.

8 Hoyt CS, Billson FA. Visual loss in osteopetrosis. $A m$ ₹ Dis Child 1979; 133: 955-8.

9 Ruben JB, Morris RJ, Judish GF. Chorioretinal degeneration in infantile malignant osteopetrosis. Am $\mathcal{f}$ Ophthalmol 1990; 110: 1-5.

10 Keith CG. Retinal atrophy in osteopetrosis. Arch Ophthalmol 1968; 79: 234-41.
An unusual impediment to spectacle wear: pilomatrixoma

EDITOR,-Pilomatrixoma or calcifying epithelioma of Malherbe is a relatively uncommon benign skin tumour arising from cells of the hair follicle. Sixty per cent present during the first two decades of life although pilomatrixoma can occur at any age. ${ }^{1}$ It is more common in females by a ratio of 3:2. Although pilomatrixoma has a predilection for the upper lid and eyebrow, ${ }^{23}$ each ophthalmologist will see a relatively small number. A case of pilomatrixoma is presented with discussion of its management.

\section{CASE REPORT}

A 48-year-old woman developed a 'thumb sized' lump on her left upper eyelid over the course of 1 year. Because of a pathological fear of doctors and hospitals she had delayed her presentation until the size of the lump interfered with her wearing of spectacles.

She attended the clinic with a gauze dressing attached to her spectacle frame with which she had been attempting to conceal the mass's increasing bulk. On examination she was found to have a very large tumour, approximately $6 \mathrm{~cm}$ long and $3 \mathrm{~cm}$ in diameter, attached by a broad base to the left upper eyelid and anterior aspect of the temporal region. Granulation tissue was evident on the surface with a purulent discharge (Fig 1A) There was no evidence of local or systemic metastasis.

She underwent primary diagnostic excision of the tumour, and since the patient insisted upon local anaesthesia and day-case surgery, the tissue defect was left to heal by secondary intention (Fig 1B).

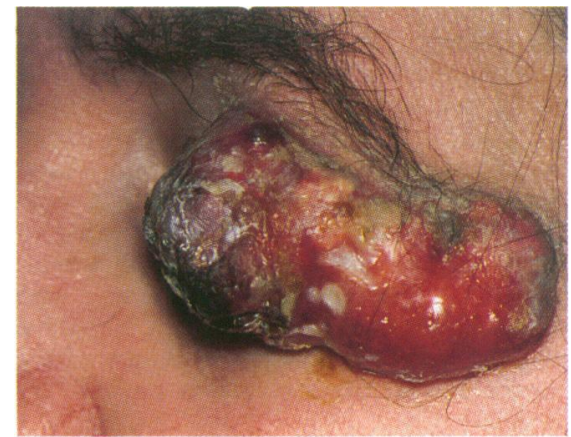

Fig 1 A

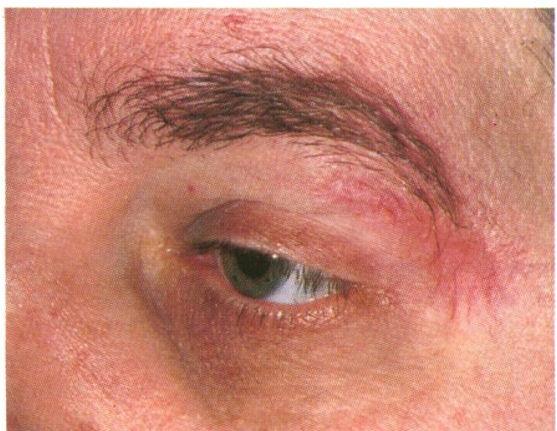

Fig $1 B$

Figure 1 (A) A large $6 \mathrm{~cm}$ by $3 \mathrm{~cm}$ tumour mass involving the left upper lid and temporal region. The mass demonstrates granulation tissue with a mild purulent discharge. The patient had disguised this mass by means of a gauze dressing attached to her spectacle frame. (B) Appearance of left upper lid and brow 6 months after primary excision of pilomatrixoma allowing large wound defect to heal by secondary intention. 